\title{
Influence of Several Compounds and Drugs on the Renal Uptake of Radiolabeled Affibody Molecules
}

\author{
Javad Garousi ${ }^{1}\left(\mathbb{D}\right.$, Anzhelika Vorobyeva ${ }^{1,2}$ (D) and Mohamed Altai ${ }^{3, *}$ \\ 1 Department of Immunology, Genetics and Pathology, Uppsala University, 75185 Uppsala, Sweden; \\ javad.garousi@igp.uu.se (J.G.); anzhelika.vorobyeva@igp.uu.se (A.V.) \\ 2 Research Centrum for Oncotheranostics, Research School of Chemistry and Applied Biomedical Sciences, \\ National Research Tomsk Polytechnic University, 634050 Tomsk, Russia \\ 3 Division of Oncology and Pathology, Kamprad Lab, Department of Clinical Sciences, Lund University, \\ 22243 Lund, Sweden \\ * Correspondence: mohamed.altai@med.lu.se; Tel.: +46-704128699
}

Received: 30 April 2020; Accepted: 5 June 2020; Published: 9 June 2020

check for updates

\begin{abstract}
Affibody molecules are the most studied class of engineered scaffold proteins (ESPs) in radionuclide molecular imaging. Attempts to use affibody molecules directly labelled with radiometals for targeted radionuclide therapy were hampered by the high uptake and retention of radioactivity in kidneys. Several promising strategies have been implemented to circumvent this problem. Here, we investigated whether a pharmacological approach targeting different components of the reabsorption system could be used to lower the uptake of [ $\left.{ }^{99 \mathrm{~m}} \mathrm{Tc}\right] \mathrm{Tc}-Z_{\text {HER:2395 }}$ affibody molecule in kidneys. Pre-injection of probenecid, furosemide, mannitol or colchicine had no influence on activity uptake in kidneys compared to the control group. Mice pre-injected with maleate and fructose had $33 \%$ and $51 \%$ reduction in the kidney-associated activity, respectively, compared to the control group. Autoradiography images showed that the accumulation of activity after [ ${ }^{99 \mathrm{~m}} \mathrm{Tc}$ Tc- $Z_{\text {HER2:2395 }}$ injection was in the renal cortex and that both maleate and fructose could significantly reduce it. Results from this study demonstrate that pharmacological intervention with maleate and fructose was effective in reducing the kidney uptake of affibody molecules. A presumable mechanism is the disruption of ATP-mediated cellular uptake and endocytosis processes of affibody molecules by tubular cells.
\end{abstract}

Keywords: affibody molecules; radiolabel; ${ }^{99 \mathrm{~m}} \mathrm{Tc}$; kidney; reabsorption; renal uptake

\section{Introduction}

Advances in protein engineering such as molecular display techniques made it possible to generate alternatives to monoclonal antibodies (mAbs). A promising type of binding proteins is the non-immunoglobulin engineered scaffold-based affinity proteins (ESPs) [1,2]. Of these, affibody molecules have been studied the most for radionuclide-based molecular imaging [3]. Affibody molecules $(7 \mathrm{kDa})$ are scaffold proteins with a size ca. 20 -fold smaller than the size of intact $\mathrm{mAbs}$. Affibody molecules binding with high affinity to several clinically relevant cancer-associated molecular targets (HER2, EGFR, HER3, IGF-1R, PDGFR $\beta$ and CAIX) have been developed [4,5]. In molecular imaging, radiolabelled affibody molecules proved to be advantageous in comparison with mAbs enabling higher sensitivity and specificity [5]. Due to their small size, affibody molecules accumulate rapidly in tumours, undergo rapid washout from non-targeted tissues, and have a short residence time in the circulation. It was shown in preclinical studies that affibody molecules provided at least 10-fold higher imaging contrast than monoclonal antibodies [4,6]. Clinical studies have recently demonstrated that injections of affibody molecules are well-tolerated by patients and do not elicit 
immune responses, which are key parameters in the development of any therapeutic protein-based agent [7]. Several preclinical studies have demonstrated that affibody molecules have the potential to target disease-specific antigens with a therapeutic intention [8,9]. Moreover, affibody structure permits site-specific conjugation of a payload for the development of targeted therapeutic agents with well-defined pharmacokinetics. We have recently demonstrated that affibody molecules could be successfully used as targeting vehicles for the delivery of a cytotoxic drug for cancer therapy [10].

A common issue for radiometal-labelled affibody molecules is the high radioactivity retention in kidneys. The size of affibody molecules $(7 \mathrm{kDa})$ is below the kidney filtration barrier $(60 \mathrm{kDa})$, making them readily filtered through the glomerulus [3,11]. After filtration, the affibody molecules carrying radionuclides are efficiently reabsorbed in proximal tubules of kidneys. If the label has residualizing properties, which is the case for most radiometals, the activity is retained in the tubular cells. This prevents the use of affibody molecules for targeted radionuclide therapy. Kidneys are radiosensitive organs and their exposure to high doses of activity used in therapy might result in renal damage and loss of function. There were several methods developed by other groups for reduction of renal uptake of radiolabelled proteins and peptides, such as infusion of basic amino acids or the gelatine-based plasma expander, Gelofusine. However, these methods were inefficient in the case of affibody molecules [11]. We have found that the renal reabsorption of anti-HER2 affibody molecules is mediated by an unknown scavenger receptor and that the amino acids comprising the HER2-binding site are involved in this process. The binding site is crucial for target recognition, and its re-engineering to reduce renal reabsorption of affibody molecules is practically impossible without compromising binding to the target.

Earlier, we succeeded in reducing the renal retention of radioactivity delivered by affibody molecules through the development of an innovative radiolabelling strategy that generated more "leaky" radiocatabolites escaping out of tubular cells. These efforts resulted in the development of anti-HER2 affibody molecule $Z_{\mathrm{HER} 2 \mathrm{~V} 2}$ labelled with the cytotoxic radionuclide rhenium-188 that could deliver high absorbed doses to tumours without exceeding kidney and bone marrow toxicity limits [12]. However, this kidney-preserving chemistry cannot be extended to other clinically relevant radiometals ${ }^{177} \mathrm{Lu},{ }^{225} \mathrm{Ac}$ and ${ }^{227} \mathrm{Th}$ due to differences in chemical properties between rhenium and these radiometals.

An alternative strategy that permitted the use of affibody molecules for targeted radionuclide therapy was pretargeting. Pretargeting or multi-step targeting approach has been first applied to overcome the limitations associated with the use of directly radiolabelled mAbs in therapy [13]. We developed a novel pretargeting strategy based on affibody molecules and mediated by peptide nucleic acids (PNA) hybridization [14,15]. Using affibody-based PNA-mediated pretargeting, we obtained a 5-fold higher radioactivity accumulated dose to the tumour than to the kidneys. This approach provided doubling of median survival of ${ }^{177} \mathrm{Lu}$-pretargeted mice compared to control groups in preclinical setting [15].

Tolmachev et al. have developed a plasma half-life extension strategy based on coupling of affibody molecules to an albumin binding domain (ABD) aiming to increase the overall size and hydrodynamic radius of the affibody above the glomerular filtration barrier [16]. In vivo, fusion with ABD enabled a 25-fold reduction of renal uptake in comparison with the non-fused affibody molecule. Using this strategy for targeted delivery of ${ }^{177} \mathrm{Lu}$ to HER2-expressing xenografts, they demonstrated that a single administration of ${ }^{177} \mathrm{Lu}-\mathrm{CHX}-\mathrm{A}^{\prime \prime}-\mathrm{DTPA}-\mathrm{ABD}-\left(\mathrm{Z}_{\mathrm{HER} 2: 342}\right)_{2}$ completely prevented the formation of tumours in mice.

The aforementioned strategies to reduce kidney uptake of affibody molecules are based on modulation of the physicochemical properties of the targeting moiety or properties of radionuclides and are developed for a given radiolabel-affibody combination. In this work, we intended to investigate whether a general pharmacological approach could be used for reduction of uptake of radiolabelled affibody molecules in kidneys. Such pharmacological approaches have been exploited earlier to 
reduce renal uptake of other peptide- and protein-based radiopharmaceuticals, such as somatostatin analogues [17-19] and designed ankyrin repeat proteins (DARPins) [20].

\section{Results}

Radiolabelling of $\mathrm{Z}_{\mathrm{HER2} 22395} \mathrm{C}$ affibody molecule with $\left[{ }^{99 \mathrm{~m}} \mathrm{Tc}\right] \mathrm{Tc}$ was performed in $96.5 \pm 1.5 \%$ chemical yield and 100\% radiochemical purity. Maleate, colchicine, probenecid, fructose, furosemide and mannitol act on various parts of the reabsorption system in kidneys and have been previously shown to interfere with the reabsorption of protein-based agents. To investigate their effect on reabsorption of affibody molecules in the kidneys, they were administered to healthy female NMRI mice prior to the injection of $\left[{ }^{99 \mathrm{~m}} \mathrm{Tc}\right] \mathrm{Tc}-Z_{\mathrm{HER} 2: 2395}$ (Table 1). The control group received a single injection of [ $\left.{ }^{99 \mathrm{~m}} \mathrm{Tc}\right] \mathrm{Tc}-Z_{\mathrm{HER} 2: 2395}$. The effect on biodistribution and kidney uptake was evaluated $4 \mathrm{~h}$ post $\left[{ }^{99 \mathrm{~m}} \mathrm{Tc}\right] \mathrm{Tc}-Z_{\text {HER:2395 }}$ injection. Kidney uptake of activity in the maleate group was 1.5 -fold $(101.2 \pm 9.6 \% \mathrm{ID} / \mathrm{g})$ lower than in the control group (151.3 $\pm 21.3 \% \mathrm{ID} / \mathrm{g})$ (Table 2 and Figure 1$)$. A one-way ANOVA test did not reveal any significant differences $(p>0.05)$ in activity uptake in other organs or tissues. Fructose reduced the kidney uptake of [ $\left.{ }^{99 \mathrm{~m}} \mathrm{Tc}\right] \mathrm{Tc}-Z_{\text {HER2:2395 }}$ by 2 -fold $(74.1 \pm 6.4 \%$ ID/g) compared to the control group. However, an increased activity uptake was observed in the blood and other normal tissues (Table 2). No difference in the kidney uptake was observed in groups that received colchicine, furosemide, probenecid and mannitol compared to the control (Table 2 and Figure 1).

Table 1. List of compounds administered before the injection of [ $\left.{ }^{99 \mathrm{~m}} \mathrm{Tc}\right] \mathrm{Tc}-\mathrm{Z}_{\mathrm{HER2} 22395}$ in Naval Medical Research Institute (NMRI) mice.

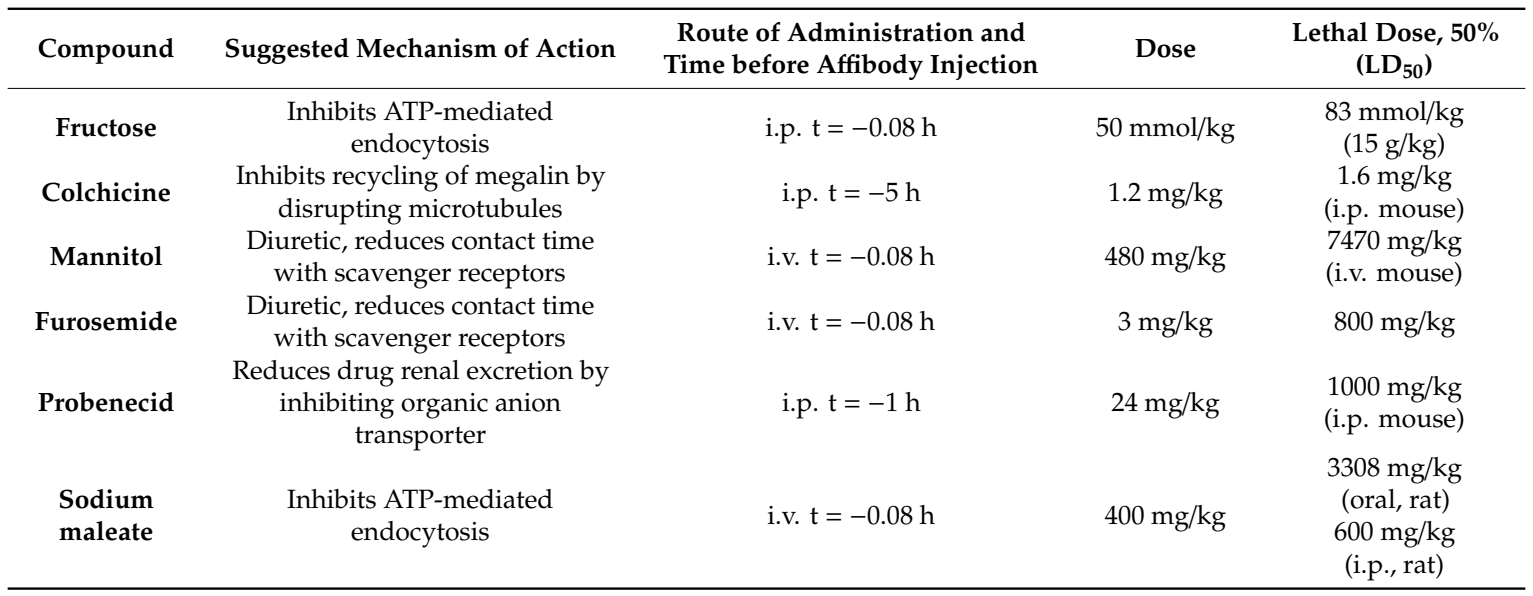

Table 2. Biodistribution of [ $\left.{ }^{99 \mathrm{~m}} \mathrm{Tc}\right] \mathrm{Tc}-\mathrm{Z}_{\mathrm{HER} 2: 2395}$ in NMRI mice $4 \mathrm{~h}$ after injection alone (control) or after administration of compounds.

\begin{tabular}{ccccccc}
\hline & Blood & Salivary Glands & Liver & Spleen & GI Tract & Carcass \\
\hline Control & $0.15 \pm 0.06$ & $0.37 \pm 0.19$ & $1.53 \pm 0.59$ & $0.36 \pm 0.09$ & $2.25 \pm 0.49$ & $2.93 \pm 0.68$ \\
Probenecid & $0.17 \pm 0.02$ & $0.36 \pm 0.01$ & $1.79 \pm 0.21$ & $0.51 \pm 0.07$ & $3.2 \pm 1.53$ & $3.34 \pm 0.27$ \\
Furosemide & $0.22 \pm 0.04$ & $0.46 \pm 0.15$ & $2.16 \pm 0.16$ & $0.57 \pm 0.11$ & $3.08 \pm 0.77$ & $3.97 \pm 0.58$ \\
Mannitol & $0.2 \pm 0.04$ & $0.48 \pm 0.13$ & $1.77 \pm 0.35$ & $0.47 \pm 0.07$ & $2.27 \pm 0.42$ & $3.42 \pm 0.64$ \\
Colchicine & $0.36 \pm 0.04 *$ & $0.89 \pm 0.12 *$ & $1.21 \pm 0.27$ & $1.16 \pm 0.24 *$ & $2.06 \pm 0.51$ & $5.69 \pm 0.39 *$ \\
Maleate & $0.17 \pm 0.02$ & $0.32 \pm 0.04$ & $2.02 \pm 0.23$ & $0.47 \pm 0.03$ & $3.37 \pm 1.73$ & $3.71 \pm 0.38$ \\
Fructose & $1.75 \pm 0.13 *$ & $1.2 \pm 0.14 *$ & $4.02 \pm 0.62 *$ & $2.07 \pm 0.42 *$ & $4.89 \pm 0.67 *$ & $21.5 \pm 3.23 *$ \\
\hline
\end{tabular}

The activity in blood, salivary gland, liver and spleen is presented as \% ID/g; for gastrointestinal (GI) tract and carcass is presented as \%ID per whole sample. The values for the treated groups are presented as an average from four animals \pm standard deviation (SD), for the control group-as an average of eight animals \pm SD. Asterisk $\left(^{*}\right)$ indicates a significant difference between control and the treated group $\left(^{*} p<0.01\right.$, one-way ANOVA test). 

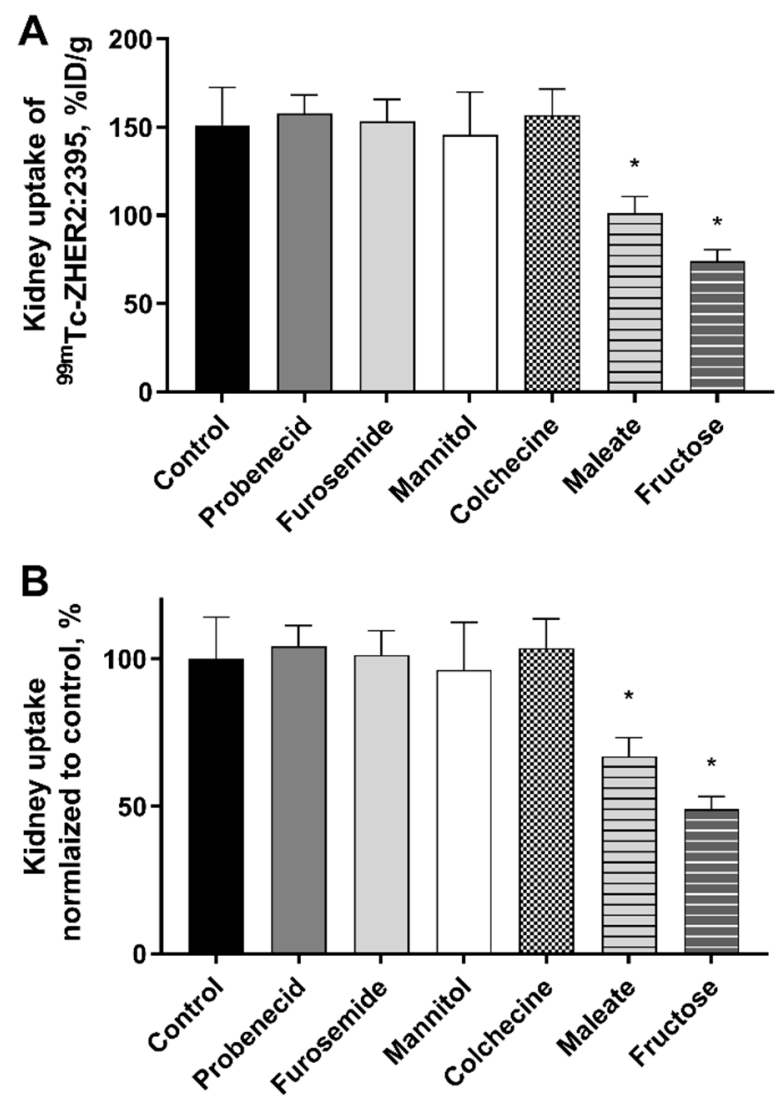

Figure 1. Kidney uptake of $Z_{\text {HER2:2395 }}$ affibody molecule labelled with ${ }^{99 \mathrm{~m}} \mathrm{Tc}$ in NMRI mice $4 \mathrm{~h}$ after injection. (A) The effect of various compounds on the kidney uptake of [ $\left.{ }^{99 m} \mathrm{Tc}\right] \mathrm{Tc}-Z_{\mathrm{HER}: 2395}$ represented as \% ID/g. (B) The kidney uptake normalized to control in \%. Data are expressed as an average of four animals \pm SD. Asterisk $\left(^{*}\right)$ indicates a significant difference between control and the treated group (* $p<0.001$, one-way ANOVA test).

Autoradiograms of kidney sections of mice from the control and treated groups showed that the activity was mainly localized in the renal cortex for all studied groups (Figure 2). The level of activity in maleate and fructose treated groups was noticeably lower compared to the control (Figure 2B).

A
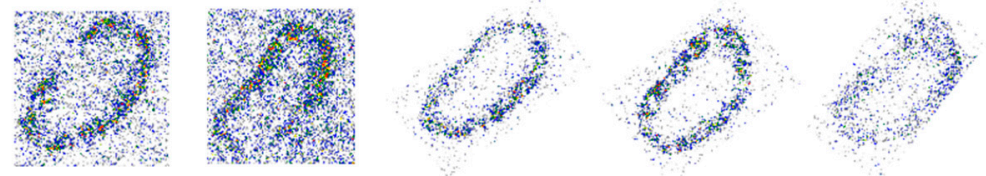

Control Colchicine

B

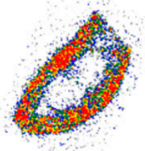

Control

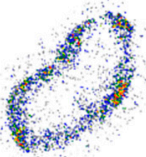

Maleate
Probenecid Furosemide Mannitol
1900

1515

Figure 2. Representative ex vivo autoradiograms of kidney slices. NMRI mice were pre-injected with (A) colchicine, probenecid, furosemide, mannitol, (B) maleate and fructose prior to the injection of [ $\left.{ }^{99 \mathrm{~m}} \mathrm{Tc}\right] \mathrm{Tc}-Z_{\mathrm{HER} 2: 2395}$. In the control groups mice were injected with [ $\left.{ }^{99 \mathrm{~m}} \mathrm{Tc}\right] \mathrm{Tc}-Z_{\mathrm{HER}: 2395}$ only and sacrificed $4 \mathrm{~h}$ post injection. 


\section{Discussion}

ESPs and protein-based targeting agents below $60 \mathrm{kDa}$ are readily reabsorbed in the renal tubular cells after glomerular filtration. Following reabsorption, lysosomal degradation of radiometal-labelled affibody molecules in the tubular cells generates "non-leaky", residualizing radiocatabolites that are retained inside cells. This renders the radiosensitive kidney more prone to harmful radiation in targeted radionuclide therapy. Therefore, the use of affibody molecules for targeted radionuclide therapy is hampered by this elevated renal uptake of radioactivity. Direct pharmacological intervention using megalin blockers, Gelofusine and lysine, had no influence on the kidney uptake of affibody molecules [11]. Alternative strategies to reduce the renal accumulation of radioactivity observed with radiometal-labelled affibody molecules have resulted in several advancements [11,12,15,21-27]. In particular, the pretargeting and plasma half-life extension strategies demonstrated promising results in preclinical settings $[15,16]$. In this study, we extend on previous efforts by investigating whether the renal uptake of [ $\left.{ }^{99 \mathrm{~m}} \mathrm{Tc}\right] \mathrm{Tc}-Z_{\mathrm{HER} 2: 2395}$ affibody molecule could be reduced by administration of other drugs and compounds that are known to act on different parts of the renal excretion pathway.

Colchicine is an anti-gout drug that interferes with the process of endocytosis mainly by inhibiting the microtubules polymerization and hence disrupting intracellular trafficking of organelles between different cell compartments [28]. Disruption of intracellular trafficking may interfere with the turnover/recycling of megalin scavenger receptor back to the luminal membrane. Rolleman et al. have shown that colchicine efficiently blocked the tubular uptake of the somatostatin analogue, [111 In]In-DTPA-octreotide, in rat kidneys in a dose-dependent manner [17]. No effect of colchicine was observed with affibody molecules in the current study (Figure 1, Table 2). This lack of effect by colchicine was also observed for another class of ESPs, DARPins [20].

Next, we investigated if maleate would have any influence on the kidney uptake of affibody molecules. Maleate has been used in rats to induce an experimental model of Fanconi syndrome [29,30]. Maleate reduces cellular ATP by interfering with the citric acid cycle [31] and disrupts the energy-mediated endocytosis process. It was also proposed that maleate specifically inhibits membrane recycling of megalin during endocytosis [32]. However, Melis et al. have shown that megalin expression was not affected by maleate injections [19]. They have also demonstrated that the administration of sodium maleate reduced the renal uptake of [ ${ }^{111} \mathrm{In}$ ]In-DTPA-octreotide by $85 \%$ compared to the control group. An important finding was the less impressive reduction of renal uptake when maleate was given hours prior to the administration of the radiolabelled peptide, thus indicating a transient effect of maleate. Based on that, and in order to maximize the effect of maleate, we have chosen to administer maleate shortly before the injection of [ $\left.{ }^{99 \mathrm{~m}} \mathrm{Tc}\right] \mathrm{Tc}-Z_{\text {HER2:2395 }}$ affibody molecule. Interestingly, we have observed a significant $33 \%$ decrease in the kidney activity uptake compared with the control group. It is worth mentioning that the convoluted segments of the proximal tubules, where reabsorption mainly takes place, are confined entirely to the renal cortex. Autoradiograms of kidney sections from the maleate group have demonstrated a reduction in the accumulated radioactivity in the cortex (Figure 2), which is in line with the biodistribution results.

Fructose is another compound that decreases intracellular ATP in liver and kidneys mainly through the sequestration of phosphates into metabolic intermediates [33]. Fructose injections in mice dramatically reduced tubular ATP in a dose-dependent manner. Doses of up to $20 \mathrm{mmol} / \mathrm{kg}$ fructose did not decrease the kidney uptake of [ $\left.{ }^{111} \mathrm{In}\right] \mathrm{In}$-DTPA-octreotide [17]. Mice in the current study were injected with $50 \mathrm{mmol} / \mathrm{kg}$ fructose immediately before the administration of [ $\left.{ }^{99 \mathrm{~m}} \mathrm{Tc}\right] \mathrm{Tc}-Z_{\text {HER2:2395 }}$ affibody molecule. We observed a 2-fold decrease in the kidney-associated radioactivity compared with the control group. Interestingly, liver and blood activity levels were significantly elevated by fructose, but not by maleate (Table 2). We speculate that the higher accumulation of radioactivity in organs and blood in the presence of fructose could be due to reduced renal function imposed by the ketonic monosaccharide. The injected dose of fructose used in this study is close to the $\mathrm{LD}_{50}$ of the compound $(80 \mathrm{mmol} / \mathrm{kg})$, thus, it is of interest to see if lower doses or different administration schedules could provide a similar effect. 
It was documented in the literature that the proximal tubules express various forms of organic transporters [34,35]. We tested if the anti-gout drug probenecid, known to inhibit organic anion transporters (OATs) and renal excretion of some drugs, would have any effect on the renal uptake of [ $\left.{ }^{99 \mathrm{~m}} \mathrm{Tc}\right] \mathrm{Tc}-\mathrm{Z}_{\mathrm{HER} 2: 2395}$. Earlier, Stahl et al. reported that probenecid administration reduced kidney uptake of [ $\left.{ }^{111} \mathrm{In}\right] \mathrm{In}$-DOTATOC by 30\% [18]. However, administration of probenecid did not reduce the kidney uptake of affibody molecules (Figures 1 and 2). This lack of probenecid effect was also observed for DARPins [20]. Together these data suggest that OATs do not play a significant role in the uptake of affibody molecules by the proximal tubular cells.

Furosemide, a loop diuretic, may affect the urinary and plasma concentrations of some co-administered drugs by either increasing the glomerular filter load or inducing an increased renal excretion in the tubules [36]. Mannitol is an osmotic diuretic which may induce forced diuresis, enhancing the elimination of certain drugs and toxins from the body. Both furosemide and mannitol had no effect on renal radioactivity accumulation post- $\left[{ }^{99 \mathrm{~m}} \mathrm{Tc}\right] \mathrm{Tc}-\mathrm{Z}_{\mathrm{HER} 2: 2395}$ injection. These results indicate that the capacity of reabsorption of small proteins, specifically affibody molecules, is neither dependent on the filter volume or load, nor on its rate of flow.

Although interesting, the effect of fructose and maleate on the kidney uptake of radiolabelled affibody molecules is suboptimal and hence cannot justify the use of these drugs in radionuclide therapy protocols involving radiolabelled affibody molecules. We believe that findings from this study may help in understanding the underlying mechanism of kidney uptake of affibody molecules, as well as be of help for researchers working with other classes of targeting agents with elevated kidney uptake. A similar approach may provide an indication for researchers whether they should optimize therapy protocols by co-administering blocking agents or adopt more efficient strategies, for example, pretargeting or plasma half-life extension. We, therefore, recommend not to generalize the findings from this study to other classes of targeting agents and that the kidney uptake lowering strategies should be evaluated for each class on a case-by-case basis.

\section{Materials and Methods}

Technetium pertechnetate ${ }^{99} \mathrm{TcO}_{4}{ }^{-}$was provided by elution of ${ }^{99} \mathrm{Mo} /{ }^{99 \mathrm{~m}} \mathrm{Tc}$ generator (Mallinckrodt-Tyco, Petten, The Netherlands) with sterile saline solution. Sodium maleate, D-fructose, colchicine, probenecid and L-lysine were purchased from Sigma (Sigma-Aldrich, Saint Luis, MO, USA). Furosemid (Takeda Pharma AB, Stockholm, Sweden), mannitol (Fresenius Kabi AB, Uppsala, Sweden), and Gelofusine (B. Braun Melsungen AG, Melsungen, Germany) were purchased as solutions for injections. Radioactivity was measured by an automated $\gamma$-spectrometer with a $\mathrm{NaI}(\mathrm{Tl})$ detector (1480 Wizard, Wallac, Turku, Finland).

\subsection{Labelling of $Z_{H E R 2: 2395}$ with ${ }^{99 m} T C$}

Affibody molecules $Z_{\text {HER2:2395 }}$ were produced and purified as described by Ahlgren et al. [21]. Labelling was performed using a freeze-dried kit, containing $5 \mathrm{mg}$ sodium $\alpha$-D-glucoheptonate (Celsus Laboratories, Geel, Belgium), $75 \mu \mathrm{g} \mathrm{SnCl}$ (Fluka Chemika, Buchs, Switzerland) and $100 \mu \mathrm{g}$ of EDTA (Sigma-Aldrich, Munich, Germany), as described earlier [37,38]. The lyophilized $Z_{\text {HER2:2395 }}$ $(50 \mu \mathrm{g})$ was reconstituted in $50 \mu \mathrm{L}$ degassed PBS and the solution was added to the content of one freeze-dried kit. Eluate containing ${ }^{99 \mathrm{~m}} \mathrm{Tc}(100 \mu \mathrm{L})$ was added. The mixture was incubated for $40 \mathrm{~min}$ at $95^{\circ} \mathrm{C}$. The conjugate was purified using a disposable NAP-5 size-exclusion column. To determine the radiochemical yield and radiochemical purity, iTLC-SG strips (Varian, Lake Forest, CA, USA) were eluted with PBS.

\subsection{Compounds Acting on Tubular Reabsorption}

A list of different compounds and drugs used in this study and their proposed mechanisms of action are shown in Table 1. 


\subsection{Animal Studies}

All experiments had been approved by the Ethics Committee for Animal Research in Uppsala County (Permit Number: C4/ 2016) and were performed according to the Swedish laws on laboratory animal welfare. Thirty-two female NMRI mice, divided into eight groups of four mice, were used in the experiments. The average mouse weight was $27 \pm 3 \mathrm{~g}$, and the average kidney weight was $272 \pm 35 \mathrm{mg}$ at the start of the experiment. Mice and kidney weights did not differ significantly $(p>0.05$, one-way ANOVA test) between the groups. For all experiments, $1 \mu \mathrm{g}(60 \mathrm{kBq})$ of [ $\left.{ }^{99 \mathrm{~m}} \mathrm{Tc}\right] \mathrm{Tc}-\mathrm{Z}_{\mathrm{HER} 2: 2395}$ affibody molecule was injected intravenously into the tail vein $(100 \mu \mathrm{L})$. In the treatment groups, mice were pre-injected with probenecid $(20 \mathrm{mg} / \mathrm{kg}, 1 \mathrm{~h}$, i.p.), furosemide $(2.5 \mathrm{mg} / \mathrm{kg}, 5 \mathrm{~min}$, i.v.), mannitol ( $400 \mathrm{mg} / \mathrm{kg}, 5 \mathrm{~min}$, i.v.), colchicine ( $1 \mathrm{mg} / \mathrm{kg}, 5$ h, i.p.), maleate $(400 \mathrm{mg} / \mathrm{kg}, 5 \mathrm{~min}$., i.v.) and fructose $\left(50 \mathrm{mmol} / \mathrm{kg}\right.$. $5 \mathrm{~min}$, i.p.) prior to the injection of [ $\left.{ }^{99 \mathrm{~m}} \mathrm{Tc}\right] \mathrm{Tc}-\mathrm{Z}_{\mathrm{HER} 2: 2395}$ affibody molecule. Control groups were injected with $\left[{ }^{99 \mathrm{~m}} \mathrm{Tc}\right] \mathrm{Tc}-Z_{\mathrm{HER} 2: 2395}$ only. Animals were euthanized and dissected $4 \mathrm{~h}$ after injection of [ $\left.{ }^{99 \mathrm{~m}} \mathrm{Tc}\right] \mathrm{Tc}-\mathrm{Z}_{\mathrm{HER} 2: 2395}$ and organs were collected and measured for radioactivity using an automated gamma counter.

\subsection{Autoradiography}

Autoradiographic images of the kidneys from treated mice were acquired and compared with controls. After the completion of gamma counter measurements, two pairs of kidneys were taken from each group, and were then embedded in the OCT cryomedium, frozen at $-80^{\circ} \mathrm{C}$, cut in $30 \mu \mathrm{m}$ thick serial sections using a cryomicrotome, and thaw-mounted on glass slides. The slides with sections were exposed to phosphor screens overnight, scanned using a Cyclone Storage Phosphor System at a resolution of $600 \mathrm{dpi}$ and analysed with OptiQuant image analysis software (Perkin Elmer, Waltham, MA, USA).

The study was done in two days. Day 1 included treatment groups and a control group, shown in Figure 2A, and day 2 included treatment groups and a control group shown in Figure 2B. The kidney sections represented in every panel were simultaneously exposed to one phosphor screen and the signal was acquired for the same period of time. The phosphor screens capture the activity and are scanned by the instrument's laser to create a high-resolution digitized image with quantitative data. Each pixel in the image contains an intensity value. The colour range represents the range of intensity (unit per pixel) in the bitmap image. The range is determined by the minimum (Min) and maximum (Max) parameters and the colours can be adjusted manually. The relationship between intensity values in the image bitmap and colours was set to linear. The colours in the autoradiograms were adjusted to provide the maximal contrast to background.

\subsection{Statistical Analysis}

GraphPad Prism version 8.00 for Windows (GraphPad Software, San Diego, CA, USA) was used for statistical analysis. Biodistribution data were analysed using descriptive and dispersion statistics to measure; the frequency (percentage), distribution or central tendency (mean), dispersion or variation (standard deviation and one-way ANOVA test). The one-way ANOVA was evaluated with Bonferroni correction for multiple comparisons.

Author Contributions: Conceptualization, M.A.; data curation, J.G., A.V. and M.A.; investigation, A.V.; methodology, M.A.; project administration, M.A.; validation, J.G., A.V. and M.A.; writing-original draft, J.G., A.V. and M.A.; writing—review \& editing, A.V. and M.A. All authors have read and agreed to the published version of the manuscript.

Funding: This research received no external funding.

Acknowledgments: The authors thank Anna Orlova for the excellent technical assistance.

Conflicts of Interest: This research was funded by the Ministry of Science and Higher Education of the Russian Federation (075-15-2019-1925, A.V.) and the Swedish Society for Medical Research (P16-0100, M.A.). The funders had no role in the study design, data collection and analysis, decision to publish, or preparation of the manuscript. 


\section{Abbreviations}

$\begin{array}{ll}\text { HER2 } & \text { Human Epidermal growth factor type-2 } \\ \text { ABD } & \text { Albumin Binding Domain } \\ \text { DARPins } & \text { Designed Ankyrin Repeat Proteins } \\ \text { ESPs } & \text { Engineered Scaffold-based affinity Proteins } \\ \text { mAbs } & \text { Monoclonal antibodies } \\ \text { OATs } & \text { Organic anion transporters } \\ \text { PNA } & \text { Peptide nucleic acids } \\ \text { i.p. } & \text { Intraperitoneal injection } \\ \text { i.v. } & \text { Intravenous injection } \\ \text { \%ID/g } & \text { Uptake represented as percent of injected dose per gram of tissue }\end{array}$

\section{References}

1. Löfblom, J.; Frejd, F.Y.; Ståhl, S. Non-immunoglobulin based protein scaffolds. Curr. Opin. Biotechnol. 2011, 22, 843-848. [CrossRef] [PubMed]

2. Jost, C.; Plückthun, A. Engineered proteins with desired specificity: DARPins, other alternative scaffolds and bispecific IgGs. Curr. Opin. Struct. Biol. 2014, 27, 102-112. [CrossRef] [PubMed]

3. Frejd, F.Y.; Kim, K.T. Affibody molecules as engineered protein drugs. Exp. Mol. Med. 2017, 49 , e306. [CrossRef] [PubMed]

4. Altai, M.; Orlova, A.; Tolmachev, V. Radiolabeled probes targeting tyrosine-kinase receptors for personalized medicine. Curr. Pharm. Des. 2014, 20, 2275-2292. [CrossRef]

5. Tolmachev, V.; Orlova, A. Affibody Molecules as Targeting Vectors for PET Imaging. Cancers 2020, 12, 651. [CrossRef]

6. Malmberg, J.; Sandström, M.; Wester, K.; Tolmachev, V.; Orlova, A. Comparative biodistribution of imaging agents for in vivo molecular profiling of disseminated prostate cancer in mice bearing prostate cancer xenografts: Focus on 111In- and 125I-labeled anti-HER2 humanized monoclonal trastuzumab and ABY-025 Affibody. Nucl. Med. Biol. 2011, 38, 1093-1102. [CrossRef] [PubMed]

7. Sörensen, J.; Velikyan, I.; Sandberg, D.; Wennborg, A.; Feldwisch, J.; Tolmachev, V.; Orlova, A.; Sandström, M.; Lubberink, M.; Olofsson, H.; et al. Measuring HER2-Receptor Expression In Metastatic Breast Cancer Using [68Ga]ABY-025 Affibody PET/CT. Theranostics 2016, 6, 262-271. [CrossRef]

8. Fleetwood, F.; Güler, R.; Gordon, E.; Ståhl, S.; Claesson-Welsh, L.; Löfblom, J. Novel affinity binders for neutralization of vascular endothelial growth factor (VEGF) signaling. Cell. Mol. Life Sci. 2016, 73, 1671-1683. [CrossRef]

9. Orlova, A.; Bass, T.Z.; Rinne, S.S.; Leitao, C.D.; Rosestedt, M.; Atterby, C.; Gudmundsdotter, L.; Frejd, F.Y.; Löfblom, J.; Tolmachev, V.; et al. Evaluation of the Therapeutic Potential of a HER3-Binding Affibody Construct TAM-HER3 in Comparison with a Monoclonal Antibody, Seribantumab. Mol. Pharm. 2018, 15, 3394-3403. [CrossRef]

10. Altai, M.; Liu, H.; Ding, H.; Mitran, B.; Edqvist, P.-H.; Tolmachev, V.; Orlova, A.; Gräslund, T. Affibody-derived drug conjugates: Potent cytotoxic molecules for treatment of HER2 over-expressing tumors. J. Control. Release 2018, 288, 84-95. [CrossRef]

11. Altai, M.; Varasteh, Z.; Andersson, K.; Eek, A.; Boerman, O.; Orlova, A. In Vivo and In Vitro Studies on Renal Uptake of Radiolabeled Affibody Molecules for Imaging of HER2 Expression in Tumors. Cancer Biother. Radiopharm. 2013, 28, 187-195. [CrossRef]

12. Altai, M.; Wållberg, H.; Honarvar, H.; Strand, J.; Orlova, A.; Varasteh, Z.; Sandström, M.; Löfblom, J.; Larsson, E.; Strand, S.-E.; et al. 188Re-ZHER2:V2, a Promising Affibody-Based Targeting Agent Against HER2-Expressing Tumors: Preclinical Assessment. J. Nucl. Med. 2014, 55, 1842-1848. [CrossRef] [PubMed]

13. Goldenberg, D.M.; Chatal, J.-F.; Barbet, J.; Boerman, O.; Sharkey, R.M. Cancer imaging and therapy with bispecific antibody pretargeting. Update Cancer Ther. 2007, 2, 19-31. [CrossRef] [PubMed]

14. Honarvar, H.; Westerlund, K.; Altai, M.; Sandström, M.; Orlova, A.; Tolmachev, V.; Karlström, A.E. Feasibility of Affibody Molecule-Based PNA-Mediated Radionuclide Pretargeting of Malignant Tumors. Theranostics 2016, 6, 93-103. [CrossRef] [PubMed] 
15. Westerlund, K.; Altai, M.; Mitran, B.; Konijnenberg, M.; Oroujeni, M.; Atterby, C.; de Jong, M.; Orlova, A.; Mattsson, J.; Micke, P.; et al. Radionuclide Therapy of HER2-Expressing Human Xenografts Using Affibody-Based Peptide Nucleic Acid-Mediated Pretargeting: In Vivo Proof of Principle. J. Nucl. Med. 2018, 59, 1092-1098. [CrossRef] [PubMed]

16. Tolmachev, V.; Orlova, A.; Pehrson, R.; Galli, J.; Baastrup, B.; Andersson, K.; Sandström, M.; Rosik, D.; Carlsson, J.; Lundqvist, H.; et al. Radionuclide Therapy of HER2-Positive Microxenografts Using a 177Lu-Labeled HER2-Specific Affibody Molecule. Cancer Res. 2007, 67, 2773-2782. [CrossRef]

17. Rolleman, E.J.; Krenning, E.P.; van Gameren, A.; Bernard, B.F.; de Jong, M. Uptake of [111In-DTPA0]Octreotide in the Rat Kidney Is Inhibited by Colchicine and Not by Fructose. J. Nucl. Med. 2004, 45, 709-713.

18. Stahl, A.R.; Wagner, B.; Poethko, T.; Perutka, M.; Wester, H.J.; Essler, M.; Heemann, U.; Schwaiger, M.; Lutz, J. Renal accumulation of [111In]DOTATOC in rats: Influence of inhibitors of the organic ion transport and diuretics. Eur. J. Nucl. Med. Mol. Imaging 2007, 34, 2129-2134. [CrossRef]

19. Melis, M.; Krenning, E.P.; Bernard, B.F.; Barone, R.; Visser, T.J.; de Jong, M. Localisation and mechanism of renal retention of radiolabelled somatostatin analogues. Eur. J. Nucl. Med. Mol. Imaging 2005, 32, 1136-1143. [CrossRef]

20. Altai, M.; Garousi, J.; Rinne, S.S.; Schulga, A.; Deyev, S.; Vorobyeva, A. On the prevention of kidney uptake of radiolabeled DARPins. EJNMMI Res. 2020, 10, 7. [CrossRef]

21. Ahlgren, S.; Orlova, A.; Rosik, D.; Sandström, M.; Sjöberg, A.; Baastrup, B.; Widmark, O.; Fant, G.; Feldwisch, J.; Tolmachev, V. Evaluation of Maleimide Derivative of DOTA for Site-Specific Labeling of Recombinant Affibody Molecules. Bioconjugate Chem. 2008, 19, 235-243. [CrossRef]

22. Altai, M.; Honarvar, H.; Wållberg, H.; Strand, J.; Varasteh, Z.; Rosestedt, M.; Orlova, A.; Dunås, F.; Sandström, M.; Löfblom, J.; et al. Selection of an optimal cysteine-containing peptide-based chelator for labeling of affibody molecules with 188Re. Eur. J. Med. Chem. 2014, 87, 519-528. [CrossRef] [PubMed]

23. Engfeldt, T.; Orlova, A.; Tran, T.; Bruskin, A.; Widström, C.; Karlström, A.E.; Tolmachev, V. Imaging of HER2-expressing tumours using a synthetic Affibody molecule containing the 99mTc-chelating mercaptoacetyl-glycyl-glycyl-glycyl (MAG3) sequence. Eur. J. Nucl. Med. Mol. Imaging 2007, 34, 722-733. [CrossRef]

24. Ekblad, T.; Tran, T.; Orlova, A.; Widström, C.; Feldwisch, J.; Abrahmsén, L.; Wennborg, A.; Karlström, A.E.; Tolmachev, V. Development and preclinical characterisation of $99 \mathrm{mTc}$-labelled Affibody molecules with reduced renal uptake. Eur. J. Nucl. Med. Mol. Imaging 2008, 35, 2245-2255. [CrossRef] [PubMed]

25. Tran, T.A.; Ekblad, T.; Orlova, A.; Sandström, M.; Feldwisch, J.; Wennborg, A.; Abrahmsén, L.; Tolmachev, V.; Karlström, A.E. Effects of Lysine-Containing Mercaptoacetyl-Based Chelators on the Biodistribution of 99mTc-Labeled Anti-HER2 Affibody Molecules. Bioconjugate Chem. 2008, 19, 2568-2576. [CrossRef]

26. Tran, T.A.; Rosik, D.; Abrahmsén, L.; Sandström, M.; Sjöberg, A.; Wållberg, H.; Ahlgren, S.; Orlova, A.; Tolmachev, V. Design, synthesis and biological evaluation of a multifunctional HER2-specific Affibody molecule for molecular imaging. Eur. J. Nucl. Med. Mol. Imaging 2009, 36, 1864. [PubMed]

27. Wållberg, H.; Orlova, A.; Altai, M.; Hosseinimehr, S.J.; Widström, C.; Malmberg, J.; Ståhl, S.; Tolmachev, V. Molecular Design and Optimization of 99mTc-Labeled Recombinant Affibody Molecules Improves Their Biodistribution and Imaging Properties. J. Nucl. Med. 2011, 52, 461-469. [CrossRef]

28. Christensen, E.I.; Verroust, P.J. Megalin and cubilin, role in proximal tubule function and during development. Pediatr. Nephrol. 2002, 17, 993-999. [CrossRef]

29. Harrison, H.E.; Harrison, H.C. Experimental Production of Renal Glycosuria, Phosphaturia, and Aminoaciduria by Injection of Maleic Acid. Science 1954, 120, 606-608. [CrossRef]

30. Kramer, H.J.; Gonick, H.C. Experimental Fanconi syndrome: I. Effect of maleic acid on renal cortical Na-K-ATPase activity and ATP levels. J. Lab. Clin. Med. 1970, 76, 799-808.

31. Rogulski, J.; Pacanis, A. Effects of maleate on CoA metabolism in rat kidney. Curr. Probl. Clin. Biochem. 1977, 8, 406-415.

32. Nagai, J.; Tanaka, H.; Nakanishi, N.; Murakami, T.; Takano, M. Role of megalin in renal handling of aminoglycosides. Am. J. Physiol. Renal Physiol. 2001, 281, F337-F344. [CrossRef]

33. Burch, H.B.; Choi, S.; Dence, C.N.; Alvey, T.R.; Cole, B.R.; Lowry, O.H. Metabolic effects of large fructose loads in different parts of the rat nephron. J. Biol. Chem. 1980, 255, 8239-8244. [PubMed] 
34. Tahara, H.; Kusuhara, H.; Endou, H.; Koepsell, H.; Imaoka, T.; Fuse, E.; Sugiyama, Y. A Species Difference in the Transport Activities of H2 Receptor Antagonists by Rat and Human Renal Organic Anion and Cation Transporters. J. Pharmacol. Exp. Ther. 2005, 315, 337-345. [CrossRef] [PubMed]

35. Enomoto, A.; Takeda, M.; Shimoda, M.; Narikawa, S.; Kobayashi, Y.; Kobayashi, Y.; Yamamoto, T.; Sekine, T.; Cha, S.H.; Niwa, T.; et al. Interaction of Human Organic Anion Transporters 2 and 4 with Organic Anion Transport Inhibitors. J. Pharmacol. Exp. Ther. 2002, 301, 797-802. [CrossRef] [PubMed]

36. Carbon, C.; Contrepois, A.; Vigneron, A.M.; Lamotte-Barrillon, S. Effects of furosemide on extravascular diffusion, protein binding and urinary excretion of cephalosporins and aminoglycosides in rabbits. J. Pharmacol. Exp. Ther. 1980, 213, 600-606.

37. Ahlgren, S.; Andersson, K.; Tolmachev, V. Kit formulation for 99mTc-labeling of recombinant anti-HER2 Affibody molecules with a C-terminally engineered cysteine. Nucl. Med. Biol. 2010, 37, 539-546. [CrossRef]

38. Ahlgren, S.; Wållberg, H.; Tran, T.A.; Widström, C.; Hjertman, M.; Abrahmsén, L.; Berndorff, D.; Dinkelborg, L.M.; Cyr, J.E.; Feldwisch, J.; et al. Targeting of HER2-Expressing Tumors with a Site-Specifically 99mTc-Labeled Recombinant Affibody Molecule, ZHER2:2395, with C-Terminally Engineered Cysteine. J. Nucl. Med. 2009, 50, 781-789. [CrossRef]

Sample Availability: Samples of the compounds are not available from the authors.

(C) 2020 by the authors. Licensee MDPI, Basel, Switzerland. This article is an open access article distributed under the terms and conditions of the Creative Commons Attribution (CC BY) license (http://creativecommons.org/licenses/by/4.0/). 